\title{
Outcome of Coronary Artery Bypass Graft Surgery with Coronary Endarterectomy
}

\author{
Ranjan R*, Adhikary AB \\ Department of Cardiac Surgery, Bangabandhu Sheikh Mujib Medical University, Dhaka, Bangladesh
}

\begin{abstract}
Background: Coronary Endarterectomy (CE) is the expulsion of the atheromatous plaque, and isolating the outer media and adventitia layers of arterial wall. Objective of this study was to review the consequences of coronary endarterectomy (CE) with coronary artery bypass grafting (CABG), and demonstrate the outcomes of this surgical technique for patients with diffuse coronary artery disease in a single surgeon's practice.

Methods: Retrospectively outcome of 1473 endarterectomised coronary artery in 1189 patients with diffuse coronary artery disease (CAD) was reviewed, who have had experienced CE with OPCABG in the year of 2007 to 2016. CE was performed in multi-segmental diffuse CAD, or when a calcified or extremely thick plaque making anastomosis troublesome.

Results: Approximately 75.0\% coronary endarterectomy were performed in the left coronary territory and most commonly left anterior descending artery was endarterectomized (42.83\%). An average of 1.2 coronary endarterectomies performed per patient. Post-operative ICU and 30-days mortality rate was $2.2 \%$, and $0.6 \%$ respectively in CE group. Post-operative atrial fibrillation, acute MI, neurological complication, and blood transfusion were significantly higher in CE group. Following CE, Kaplan-Meier cumulative survival rate was $89.5 \%$, and about $85 \%$ patients were free from angina at follow-up of 5 years.

Conclusion: Coronary endarterectomy with OPCABG is attainable, and accomplishes surgical revascularization in patients; when there is no other alternative for total myocardial revascularization.
\end{abstract}

Keywords: Coronary endarterectomy, Coronary artery disease, Coronary artery bypass graft

\section{Introduction}

Ischaemic heart disease (IHD) patients, who are referred for coronary artery bypass graft (CABG) surgery are progressively getting more complex with multiple comorbidities, and subsequently, this group of patients have diffuse coronary artery disease, which has made complete surgical revascularization more difficult. ${ }^{1}$ In the late 1957, coronary endarterectomy was at first presented as a surgical option for myocardial revascularization by Bailey et $\mathrm{al}^{2}$ Coronary Endarterectomy (CE) is the expulsion of the atheromatous plaque, and isolating the outer media and adventitia layers of arterial wall. ${ }^{2,3}$ Initial results for coronary endarterectomy with CABG surgery was downhearted due to greater incidence of perioperative mortality and morbidity. Furthermore, the adverse effects are even more disastrous when endarterectomy is performed on a coronary artery

*Correspondence: Redoy Ranjan, Department of Cardiac Surgery, Bangabandhu Sheikh Mujib Medical University, Dhaka, Bangladesh; e-mail: redoy_ranjan@yahoo.com ORCID: https://orcid.org/0000-0003-1927-5023 that are highly pivotal to achieve optimum myocardial revascularisation especially left anterior descending (LAD) artery, where incomplete myocardial revascularisation may results in an awful clinical outcome. ${ }^{4,5}$ Inadequate myocardial revascularizations do not influence the early death rate, but rather the occurrence of restenosis which influences the long term cardiac dysfunction. These patients have more prominent repeated attacks of angina, and more noteworthy work absence rate and require a higher number of re-interventions following CABG. ${ }^{2,4,6}$

Coronary endarterectomy is frequently important to perform optimal myocardial revascularization during CABG surgery, or to encourage anastomosis of severely calcified and diffusely diseased coronary arteries. ${ }^{3,7}$ The principle indication for CE technique is the presence of diffuse coronary artery disease with leaping lesion, that are not feasible to achieve distal bypass grafting. However, coronary endarterectomy 
can be performing safely in all territories, but few authors stated that endarterectomy in left anterior descending artery may be exceptionally tricky. ${ }^{8}$ Therefore, most of the surgeons performed LAD endarterectomy in a highly selective manner, where there are no other options exist. ${ }^{9}$ Atherosclerotic plaques in LAD artery is hard and fragile in contrast to right coronary or circumflex artery, thereby increasing the incidence of plaque disruption. Moreover, branches of LAD artery like diagonal and septal artery arises in two different planes and have the chance of shearing-off the branches during extraction of the atheromatous plaque in either direction. $^{9,10}$

The fundamental concept of coronary endarterectomy in complex coronary artery disease is to extract the total atheromatous plaque, and achieve a good distal run off in diseased coronary arteries. ${ }^{11}$ However, it is disputable that the difference in positive outcomes between concurrent $\mathrm{CE}$ with $\mathrm{CABG}$ and only $\mathrm{CABG}$ procedure is due to the complexity of the coronary lesion. Moreover, authors assume that the greater risks associated with endarterectomy technique are due to the characteristics of patients where diffuse and calcified coronary lesions hatch grafting technique challenging due to the absence of a soft landing site for distal graft. ${ }^{8-10}$ Research data from the last two decades observe better long term survival rates following coronary endarterectomy in diffuse IHD patient's. ${ }^{11,12}$ However, many cardiac surgeons are still unenthusiastic to do coronary endarterectomy due to the absence of authentic guidelines as well as varying results from different cardiac centers. The aim of this retrospective study was to evaluate the both early and long term outcomes following coronary endarterectomy with coronary artery bypass graft surgery in a single surgeon's practice and to provide details regarding treatment strategies for patients having diffuse coronary artery disease.

\section{Materials and Methods}

Between the years 2007 to 2016, a retrospective analysis of total 2647 number of patients were submitted to CABG procedure with or without $\mathrm{CE}$ in a single surgeon's practice. This study was carried out at the department of cardiac surgery, Bangabandhu Sheikh Mujib Medical University and was approved by the institutional review board (IRB) of the University. A purposive sampling methods utilized to select study population, and patients were divided into 2 study groups according to types of surgery: Group-I includes combined $\mathrm{CE}$ with $\mathrm{CABG}$, and Group- II consist of isolated CABG surgery. Inclusion criteria for $\mathrm{CE}$ procedure were distal diffuse coronary artery lesion, multi-segmental lesion; or when a calcified or extremely thick plaque burst, making anastomosis troublesome or hindering the distal stream. Patient's with short segment coronary artery lesion were not included in $\mathrm{CE}$ procedure. The decisiveness to perform coronary endarterectomy was based on the findings of preoperative coronary angiograms, and majority of the endarterectomy were plan before surgery. However, the conclusive decision to have a $\mathrm{CE}$ procedure was made according to per-operation findings of the vessel conditions as well as the surgeon's preference.

Surgical technique: All procedures were performed through a standard median sternotomy and a CPB circuit was kept on standby for all cases. Heparin was used just before completing LIMA harvest to maintain an ACT (Activated clotting time) more than 350 seconds. Almost all the operations were performed off pump $\mathrm{CABG}$ and a few cases required the assistance of cardiopulmonary bypass (CPB). Mechanical stabilisers like suction type and the compression type were utilised, to immobilize the target coronary artery during grafting. A conclusive decision to endarterectomise a vessel is made peroperatively. ${ }^{5,7}$ Coronary endarterectomies were performed manually by utilizing the closed methods"slow sustain and continuous traction" of atheromatous plaque with the aid of delicate Ring Forceps, followed by reproduction of distal anastomosis with pre-planned graft. The arteriotomy incision was roughly $8-10 \mathrm{~mm}$ long, however that was stretched out for another $5 \mathrm{~mm}$ in few cases. Much consideration was provided to the entire expulsion of the distal segment, but complete proximal endarterectomy avoided due to the danger of competitive flow loss between the graft and the native artery. ${ }^{7,11,12}$ To ensure complete expulsion, the atheromatous plaque carefully inspected for a smooth distal tapper end. In addition, back flow of blood from the distal vessel following extraction of the atheroma is a consoling indication of adequate 
removal atheromatous plaque and that is special feature in OPCABG endarterectomy. ${ }^{5,7,11-13}$ In this study, longest atheroma (14 $\mathrm{cm}$ in size) was removed from RCA and also another $10 \mathrm{~cm}$ atheromatous plaque extracted from LAD during OPCABG (figure 1).

Anticoagulation therapy: In early post-operative period, every patient received heparin infusion bridging to warfarin from the first post-operative day for next 3-6 months. Heparin was used (usually 5000 IU subcutaneously 8 hourly) in the early postoperative period, usually 3-4 hours following surgery, followed by oral warfarin $(5-10 \mathrm{mg})$ till $3^{\text {rd }}$ post-operative day. From $4^{\text {th }}$ post-operative day to onwards, warfarin was used at a dose of 2.5 to $5 \mathrm{mg}$ for next 3 to 6 months and dose was adjusted according to INR (targeted INR was 1.5-2.5). In this study, a combination of clopidogrel with aspirin (75 $\mathrm{mg}$ ) also used to anticipate acute thrombosis at the graft and also in the endarterectomies native artery for life long from $1^{\text {st }}$ post-operative day.

Study endpoints and follow-up: The primary endpoint of this study was LV function and post-procedural graft patency rate at five year follow up. LV function were classified as (a) Good LV function (EF $>50 \%$ ), (b) Moderate dysfunction (EF 30-50\%), (c) Poor LV function $(\mathrm{EF}<30 \%)$. Furthermore, graft patency rate was classified as (a) Grade A: excellent patency rate ( $\leq 50 \%$ stenosis), (b) Grade B: moderate graft stenosis ( $>50 \%$ lesion), and (c) Grade O: total graft occlusion. The patients underwent a TTE (Transthoracic Echocardiography) and CT (Computer tomography) angiogram to evaluate LV function and the degree of in-graft stenosis respectively. Moreover, the secondary study endpoint was the incidence of major adverse cardiac and cerebrovascular events (MACCE), defined as allcause death, non-fatal myocardial infarction and also cerebrovascular event during the 5-year clinical follow-up. During this study, every patient was reached either during outpatient department visit (OPD) or by phone call and data was noted to data sheet.

Statistical analysis: All statistical analyses were performed with Statistical Package for the Social Sciences. Continuous variables were expressed as mean \pm standard deviation and categorical variables as percentages. Categorical variables were compared using Pearson's chi-square and are expressed as a percentage of the group of origin. Cumulative survival rate were evaluated with the Kaplan-Meier estimation method. All reported $\mathrm{p}$ values are two-sided, and $p$ values of $\leq 0.05$ were considered statistically significant.

\section{Results}

A total of 2647 patients were undergone surgical revascularization in this review. However, 1189 patients underwent CE with CABG (Group- I), and 1458 patients underwent isolated CABG (Group- II) surgery. In Group- I 1473 coronary endarterectomies were performed, that is an average of 1.24 coronary endarterectomies performed per patient. Approximately two-third CE were performed in the left coronary territory and in $42.83 \%$ cases LAD (left anterior descending artery) required endarterectomies and grafted with LIMA (Left internal mammary artery). Used conduit for LAD graft was LIMA in $100 \%$ cases for CE with CABG group, and $99.25 \%$ in only $\mathrm{CABG}$ group. Mean number of graft were $3.21 \pm 0.25$ in CE with CABG group, and $3.02 \pm 0.15$ in only $\mathrm{CABG}$ group. There were $13.3 \%$ conversions to on-pump CABG using cardiopulmonary by pass in CE with CABG Group but only 3.84\% conversions in only CABG Group. table II.

Table I: Pre-operative characteristics of study population

\begin{tabular}{|c|c|c|c|}
\hline \multicolumn{2}{|r|}{ Variable } & $\begin{array}{c}\mathrm{CE} \text { with CABG } \\
(\mathrm{n}=1189)\end{array}$ & $\begin{array}{c}\text { Only CABG } \\
(n=1458)\end{array}$ \\
\hline \multicolumn{2}{|c|}{ Age (mean) in years } & $61.25 \pm 5.5$ & $59.75 \pm 2.5$ \\
\hline \multirow{2}{*}{ Sex } & Male & $935(78.64 \%)$ & $1094(75.03 \%)$ \\
\hline & Female & $218(21.36 \%)$ & $364(24.97 \%)$ \\
\hline \multirow{6}{*}{ Risk factors } & Hypertension & $983(82.67 \%)$ & $1186(81.34 \%)$ \\
\hline & Dyslipidemia & $916(77.03 \%)$ & $1147(78.67 \%)$ \\
\hline & Smoking & $837(70.40 \%)$ & $1068(73.25 \%)$ \\
\hline & Diabetes $\mid$ Type-1 & $423(35.58 \%)$ & $497(34.09 \%)$ \\
\hline & Mellitus $\quad$ Type-2 & $766(64.42 \%)$ & $961(65.91 \%)$ \\
\hline & $\begin{array}{l}\text { Family history of } \\
\text { IHD }\end{array}$ & $672(56.52 \%)$ & $795(54.53 \%)$ \\
\hline \multicolumn{2}{|c|}{ Previous Myocardial Ischemia } & $854(71.83 \%)$ & $1073(73.59 \%)$ \\
\hline \multirow{2}{*}{ Angioplasty } & $\begin{array}{l}\text { Left Anterior } \\
\text { Descending }\end{array}$ & $106(8.92 \%)$ & $167(11.45 \%)$ \\
\hline & $\begin{array}{l}\text { Right Coronary } \\
\text { Artery }\end{array}$ & $67(5.63 \%)$ & $97(6.65 \%)$ \\
\hline \multirow{2}{*}{$\begin{array}{l}\text { LV Ejection } \\
\text { Fraction }\end{array}$} & $\mathrm{EF}>50 \%$ & $703(59.13 \%)$ & $907(62.21 \%)$ \\
\hline & $\begin{array}{l}\text { EF } 30-50 \% \\
\text { EF }<30 \%\end{array}$ & $\begin{array}{l}359(30.20 \%) \\
127(10.67 \%)\end{array}$ & $\begin{array}{c}428(29.36 \%) \\
123(8.43 \%)\end{array}$ \\
\hline \multirow{2}{*}{ NYHA class } & $1-2$ & $406(34.15 \%)$ & $538(36.90 \%)$ \\
\hline & $3-4$ & $783(65.85 \%)$ & $920(63.10 \%)$ \\
\hline CCS Class & $\begin{array}{l}1-2 \\
3-4\end{array}$ & $\begin{array}{l}395(33.22 \%) \\
794(66.78 \%)\end{array}$ & $\begin{array}{l}529(36.28 \%) \\
929(63.72 \%)\end{array}$ \\
\hline \multicolumn{2}{|l|}{ EuroSCORE } & $5.9 \pm 1.8$ & $5.7 \pm 1.5$ \\
\hline
\end{tabular}

Note: IHD- Ischemic Heart Disease, NYHA- New York Heart Association, CCS- Canadian Cardiovascular Society, EuroSCORE- European System for Cardiac Operative Risk Evaluation. 
Table II: Operative data of study population

\begin{tabular}{|c|c|c|c|}
\hline \multicolumn{2}{|c|}{ Variables } & $\begin{array}{c}\text { CE with CABG } \\
(n=1189)\end{array}$ & Only CABG \\
\hline \multirow{4}{*}{ Number of graft } & $\mathrm{X}_{2}$ & $162(13.62 \%)$ & $259(17.76 \%)$ \\
\hline & $\mathrm{X}_{3}$ & $661(55.60 \%)$ & $951(65.23 \%)$ \\
\hline & $\mathrm{X}_{4}$ & $324(27.25 \%)$ & $209(14.34 \%)$ \\
\hline & $\mathrm{X}_{5}$ & $42(3.53 \%)$ & $39(2.67 \%)$ \\
\hline \multirow{2}{*}{$\begin{array}{l}\text { Use of Internal mammary artery } \\
\text { (IMA) }\end{array}$} & Left IMA & $1189(100 \%)$ & $1447(99.25 \%)$ \\
\hline & Right IMA & $492(41.38 \%)$ & $462(31.68 \%)$ \\
\hline \multirow{2}{*}{$\begin{array}{l}\text { Use of Cardiopulmonary Bypass } \\
\text { LM Disease }\end{array}$} & & $158(13.29 \%)$ & $56(3.84 \%)$ \\
\hline & & $152(12.78 \%)$ & $173(11.87 \%)$ \\
\hline \multirow{3}{*}{ Operative criteria } & Emergency & $16(1.35 \%)$ & $39(2.67 \%)$ \\
\hline & Urgent & $201(16.90 \%)$ & $241(16.53 \%)$ \\
\hline & Elective & $972(81.75 \%)$ & $1178(80.80 \%)$ \\
\hline \multicolumn{4}{|c|}{ Number of Endarterectomy in CE with CABG group } \\
\hline \multirow{8}{*}{ Territory of endarterectomy $(\mathrm{N}=1473)$} & LAD & $631(42.83 \%)$ & \\
\hline & $\mathrm{OM}$ & $52(3.53 \%)$ & \\
\hline & Diagonal & $298(20.23 \%)$ & \\
\hline & RCA & $242(16.43 \%)$ & \\
\hline & PDA & $119(8.08 \%)$ & \\
\hline & $\mathrm{LAD}+\mathrm{RCA}$ & $81(5.50 \%)$ & \\
\hline & LAD + Diagonal & $27(1.83 \%)$ & \\
\hline & RCA + Diagonal & $23(1.57 \%)$ & \\
\hline
\end{tabular}

Note: LAD- Left Anterior Descending, OM-Obtuse Marginal, RCA- Right Coronary Artery, PDA- Posterior Descending Artery.

There were no intra-operative mortalities in this study, however post-operative ICU mortality rate was $2.19 \%$ in Group -1, and $1.44 \%$ in Group - II. A mean of $1.75 \pm 0.5$ units of blood was transfused postoperatively in $\mathrm{CE}$ with $\mathrm{CABG}$ group, which is more than only CABG group ( $p$ value $<0.05$ ). The major postoperative morbidity and mortality were compared and there was no significant difference between two group. At 5 years follow up, about $89.10 \%$ and $87.34 \%$ patients were in regular followup in $\mathrm{CE}$ with $\mathrm{CABG}$, and only $\mathrm{CABG}$ group respectively. However, approximately $85 \%$ and $87 \%$ patients were free from angina (NYHA Class 1-2) in Group-I and Group- II respectively. With TTE evaluation, approximately $65 \%$ patient have good LV function $(\mathrm{EF}>50 \%)$ in both group, which are statistically significant $(p$ value $<0.05$ ) compared to preoperative LVFE. However, mortality rate was more common among poor LV function $(\mathrm{EF}<30 \%)$ group of patients. Postoperative CT angiogram was not available for all study population due to lack of financial support, although $135 \mathrm{CT}$ angiogram were performed and graft patency rate was $90.8 \%$ in Group-I and $91.2 \%$ in Group- II at 5 years follow up. Kaplan-Meier survival estimates in the combined CE with CABG group and isolated CABG group at 5 years were $89.48 \%$ and $91.02 \%$ respectively (figure 2). The rest of the postoperative outcome variables are listed in table III and table IV.
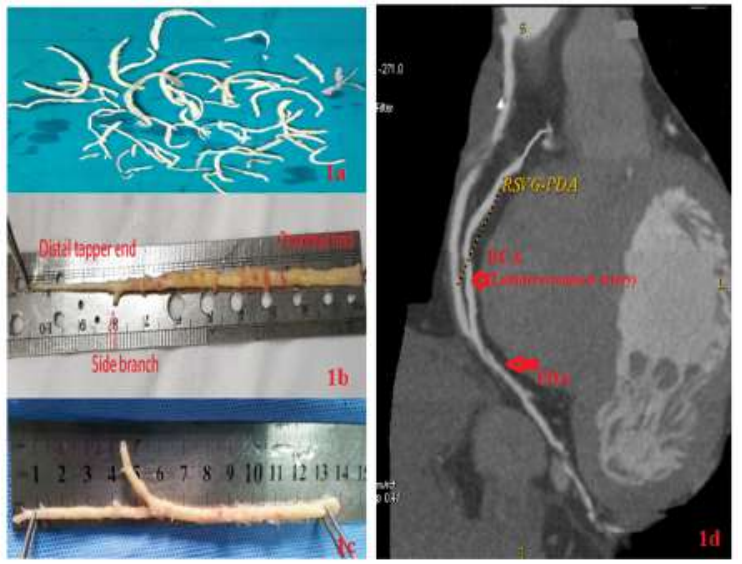

Figure 1: Photograph illustrate coronary atheroma. (Ia) Collected specimen of coronary atheroma; (Ib) Ideal atheromatous plaque having distal tapper end indicates complete endarterectomy; (Ic) Longest atheroma $(14 \mathrm{~cm})$ extracted from Right Coronary Artery (RCA); (Id) CT angiogram illustrates patent RSVG (Reverse Saphenous venous graft) to RCA following endarterectomy.

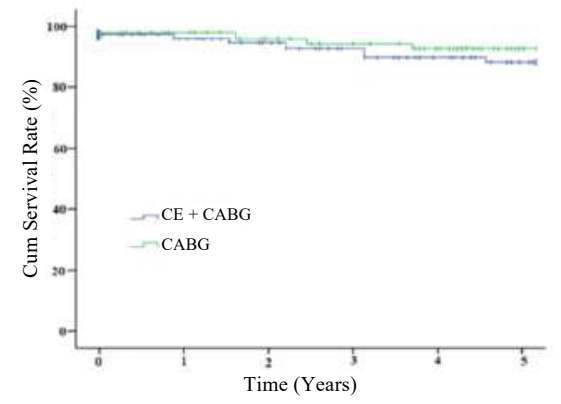

Figure 2: Kaplan-Meier survival curve demonstrates long term survival benefits between combined coronary endarterectomy with $\mathrm{CABG}$ group versus isolated $\mathrm{CABG}$ group. 
Table III: Early post-operative variables of study population

\begin{tabular}{|c|c|c|c|c|}
\hline \multicolumn{2}{|c|}{ Variables } & $\begin{array}{c}\text { CE with } \\
\text { CABG } \\
(n=1189)\end{array}$ & $\begin{array}{c}\text { Only } \\
\text { CABG } \\
(n=1458)\end{array}$ & $p$ value \\
\hline \multicolumn{2}{|c|}{ Ventilation time (hours) } & $9.9 \pm 1.25$ & $9.3 \pm 1.8$ & $<0.001$ \\
\hline \multicolumn{2}{|c|}{ ICU stay (hours) } & $36.8 \pm 6.7$ & $36.1 \pm 5.1$ & 0.002 \\
\hline \multicolumn{2}{|l|}{ ICU mortality } & $26(2.19 \%)$ & $21(1.44 \%)$ & 0.148 \\
\hline \multicolumn{2}{|c|}{30 days mortality } & $7(0.59 \%)$ & $0(0 \%)$ & 0.004 \\
\hline \multicolumn{2}{|c|}{ Hospital stay (days) } & $10 \pm 1.5$ & $10 \pm 1$ & 1.00 \\
\hline \multicolumn{2}{|c|}{ Post-operative AF } & $187(15.73 \%)$ & $152(10.43 \%)$ & $<0.001$ \\
\hline \multicolumn{2}{|c|}{ Post-operative Acute MI } & $42(3.53 \%)$ & $19(1.30 \%)$ & $<0.001$ \\
\hline \multicolumn{2}{|l|}{ Renal failure } & $27(2.27 \%)$ & $29(1.99 \%)$ & 0.715 \\
\hline \multicolumn{2}{|c|}{ Respiratory failure } & $16(1.35 \%)$ & $17(1.17 \%)$ & 0.811 \\
\hline \multirow{2}{*}{$\begin{array}{l}\text { Neurological } \\
\text { complications }\end{array}$} & TIA & $8(0.67 \%)$ & $0(0 \%)$ & 0.002 \\
\hline & Psychosis & $13(1.10 \%)$ & $12(0.82 \%)$ & 0.608 \\
\hline \multicolumn{2}{|l|}{ Use of IABP } & $15(1.26 \%)$ & $7(0.50 \%)$ & 0.047 \\
\hline \multicolumn{2}{|c|}{$\begin{array}{l}\text { Post-operative blood } \\
\text { transfusion (units) }\end{array}$} & $1.75 \pm 0.5$ & $1.25 \pm 0.5$ & $<0.001$ \\
\hline \multicolumn{2}{|c|}{$\begin{array}{l}\text { Postoperative hemorrhagic } \\
\text { complication }\end{array}$} & $12(1.01 \%)$ & $6(0.41 \%)$ & 0.104 \\
\hline
\end{tabular}

$p$ value is calculated from chi square test and $p$ value of $\leq 0.05$ are considered as statistically significant.

Note: ICU- Intensive Care Unit, AF- Atrial Fibrillation, MIMyocardial Infarction, TIA- Transient Ischemic Attack, IABPIntra-Aortic Balloon Pump.

Table IV: Long term outcome variables of study population

\begin{tabular}{|c|c|c|c|c|}
\hline \multirow{4}{*}{ Variables } & & \multirow{2}{*}{\multicolumn{2}{|c|}{$\begin{array}{c}\text { Outcome at } 5 \text { years } \\
\text { Follow up }\end{array}$}} & \multirow{4}{*}{$p$ value } \\
\hline & & & & \\
\hline & & \multirow{2}{*}{$\begin{array}{c}\text { CE with } \\
\text { CABG } \\
\end{array}$} & \multirow{2}{*}{$\begin{array}{c}\text { Only } \\
\text { CABG }\end{array}$} & \\
\hline & & & & \\
\hline \multirow{2}{*}{\multicolumn{2}{|c|}{ Survival rate at 5 years }} & 1064 & 1327 & \multirow{2}{*}{0.209} \\
\hline & & $(89.48 \%)$ & $(91.02 \%)$ & \\
\hline \multirow{4}{*}{$\begin{array}{l}\text { Follow Up } \\
\text { schedule }\end{array}$} & & 948 & 1159 & \multirow{4}{*}{0.209} \\
\hline & Regular & $(89.10 \%)$ & $(87.34 \%)$ & \\
\hline & Irreoular & 116 & 168 & \\
\hline & Irregurar & $(10.90)$ & $(12.66 \%)$ & \\
\hline \multirow{4}{*}{$\begin{array}{l}\text { NYHA } \\
\text { Functional } \\
\text { Class }\end{array}$} & & 902 & 1147 & \multirow{4}{*}{0.274} \\
\hline & $1-2$ & $(84.77 \%)$ & $(86.44 \%)$ & \\
\hline & $3-4$ & 162 & 180 & \\
\hline & $3-4$ & $(15.23 \%)$ & $(13.56 \%)$ & \\
\hline
\end{tabular}

Follow up evaluation with Transthoracic Echocardiogram (TTE)

$\begin{array}{lcccc}\text { Number of Patient } & (\mathrm{N}=865) & (\mathrm{N}=1043) & \\ & \text { EF }>50 \% & 554 & 687 & \\ \text { LV Ejection } & & (64.05 \%) & (65.87 \%) & <0.001 \\ \text { Fraction (EF) } & \text { EF } 30-50 \% & 274 & 342 & \\ & \text { EF }<30 \% & 37(4.68 \%) & (32.79 \%) & \\ & & 37 \%) & 14(1.34 \%) & \end{array}$

\begin{tabular}{lcccc}
\hline \multicolumn{4}{l}{ Follow up evaluation with CT angiogram } & \\
\hline Number of Patient $(\mathrm{N}=135)$ & $(\mathrm{N}=60)$ & $(\mathrm{N}=75)$ & \\
Number of graft $(\mathrm{n}=410)$ & $\mathrm{n}=182 \mathrm{Graft}$ & $\mathrm{n}=228 \mathrm{Graft}$ & \\
\multirow{2}{*}{ Graft patency } & Patent & $90.70 \%$ & $91.23 \%$ & 0.634 \\
rate & Stenosis & $6.59 \%$ & $6.57 \%$ & \\
& Occluded & $2.71 \%$ & $2.20 \%$ & \\
\hline
\end{tabular}

$p$ value are reached from chi square test and $p$ value $\leq 0.05$ are considered as statistically significant.

Note: NYHA- New York Heart Association, LV- Left Ventricle.

\section{Discussion}

This study evaluated the outcomes of coronary endarterectomy in CABG surgery having diffuse coronary artery disease (CAD) and shown that the complete revascularization of diffuse CAD enhanced the early and late post-operative outcomes following CABG. The mean age of study population was $61.25 \pm 5.5$ and $59.75 \pm 2.5$ in endarterectomy and only CABG group respectively. In this study, 1.24 endarterectomies required per patient in $\mathrm{CE}$ group. Out of total endarterectomies, two third endarterectomy was done in Left coronary territory, and mean graft number were $3.21 \pm 0.25$ and $3.02 \pm 0.15$ in $\mathrm{CE}$ Group and only CABG Group respectively. There were only $13.29 \%$ and $3.84 \%$ cases required cardiopulmonary bypass support in two groups respectively. Post-operative ICU mortality and 30 day's mortality rate was minimum in both study group, and all of the patients were belongs to poor LV function $(\mathrm{EF}<30 \%)$ group. In this study, a mean of more blood was transfused postoperatively in $\mathrm{CABG}$ with endarterectomy group ( $p$ value $<0.05$ ). At median follow-up of 5 years, most of the patients were angina free in both group, however, the incidence of post-operative MI and atrial fibrillation rate was higher in endarterectomy group $(p<0.05)$.

In spite of the presentation of coronary endarterectomy (CE) 60 year's prior as a strategy for treatment of diffuse coronary artery disease, its application remains controversial due to higher perioperative hazard and poor long term survival rate. ${ }^{3,8-10}$ But complete myocardial revascularization for multi vessel CAD patients has been appeared to reduce the frequency of perioperative morbidity and mortality and the duration of hospital stay. ${ }^{10-12}$ In a study, Jones et al. observed that complete myocardial revascularization appeared to be a most critical component influencing perioperative outcome, ventricular function, early and late postoperative morbidity and mortality. ${ }^{13}$ Though LAD endarterectomy is higher hazardous, however complete revascularization of the LAD is considered as a crucial determinant of the postoperative patient's recovery. ${ }^{7-10,14}$ In this study, approximately $75 \%$ of the coronary endarterectomy was performed in the left coronary territory and outcome was satisfactory. In a review, Eryilmaz et al. described that coronary endarterectomy technique as well as management yet a matter of controversy. ${ }^{15}$ However, many studies observed that closed technique for $\mathrm{CE}$ procedure is more 
straightforward, and easy to performed through small incision, and easy to reconstruction. ${ }^{3,5,12-16}$ But the potential dangers are inadequate expulsion of the plaque and the "snowplow effect," means shearing-off of the plaque in the side branches. However, with the open technique CE, the vision is better, and that may prompt more entire expulsion of the atheroma from coronary artery and also from side branches. ${ }^{10,15-17}$ Although many cardiac surgeons preferred closed traction technique for $\mathrm{CE}$, because of the open strategy is time consuming, required patch repair, and also myocardial contraction helps extraction of atheroma during offpump beating heart $\mathrm{CABG}$ which also supported by several published articles. ${ }^{5-8,16}$

Postoperative anticoagulation therapy plays a crucial role in preventing perioperative myocardial infraction following CE procedure. In a study, Papakonstantinou et al. observed that postoperative strict antiplatelet and anticoagulation management with systemic heparin infusions followed by warfarin therapy for several months provides better graft patency rate. ${ }^{18}$ Moreover, the systematic infusion of heparin is continued until warfarin is become effective with a target international normalized ratio between 2.0 and 2.5 which is similar this study results. In this study, following coronary endarterectomy, routine heparin infusion was prescribed to prevent thrombosis in graft or native endarterectomized artery, bridging to oral Warfarin for next 3 to 6 months, which is also supported by other articles. ${ }^{3,8,15-19}$ In this study postoperative ICU and 30-days mortality rate was $2.19 \%$ and $0.59 \%$ respectively, and this mortality were more common among certain group of patients like after LAD endarterectomy, multivessel $\mathrm{CE}$, and preoperative poor $\mathrm{LV}$ function $(\mathrm{EF}<30 \%)$ which is also concordance to other published articles. ${ }^{10-14,19}$ However, in a small series of study by Careaga et al. revealed a 30-day mortality of zero percent; but many authors described the average frequency of early mortality after CE with OPCABG of $2-15 \%{ }^{15-18,20}$ Furthermore, in a study, Adhikary et al. observed about $10 \%$ patients suffered from neurological complications following heart surgery, ${ }^{21}$ but in our study only $1.8 \%$ patient had postoperative neurological complications with complete recovery which agrees the findings of other studies also. ${ }^{5,8,17}$
Gill et al. demonstrate satisfactory early and late clinical results with luminal patency of IMA to an endarterectomized vessel compared to great saphenous vein conduit. ${ }^{22}$ However, Ghatanatti and Teli performed a meta-analysis involving a total of 43 recently published (year 2000-2015) research articles and observed that the present available evidence supports CE in off-pump CABG in diffuse coronary artery disease. ${ }^{23}$ Long term graft patency rate was better with open endarterectomy technique, however the survival curve remains static at 5-year follow up for both open and closed technique endarterectomy. Furthermore, Ghatanatti and Teli also observed that multi-vessel $\mathrm{CE}$ increases the overall incidence of morbidity as well as mortality, and total arterial CABG procedure is associated with better long term survival in high risk population which is concordance with this current study results. $^{23}$ In another recent study by Qiu et al. also observed that in diffuse coronary disease, $\mathrm{CE}$ is a safe and feasible procedure for a select group of patients with excellent mid-term survival rates as well as graft patency rates. ${ }^{24} \mathrm{CE}$ provides better overall outcomes when performed on the LAD artery, and grafted over with the LIMA conduit. Coronary endarterectomy offers an alternative choice of coronary artery reconstruction and complete myocardial revascularization in a selective group of patients which is supported by other authors also. ${ }^{3,8,19-23}$ In a study Naseri et al. demonstrate higher incidence of completely blocked or significant stenosis in graft and endarterectomized artery on CT angiogram and a higher incidence of (6.8\%) postoperative MI rate. ${ }^{25}$ Nevertheless, in this study, graft patency rate evaluation with CT angiogram revealed 90.70\% patency rate at 5 year's follow-up, which is also similar to other recent study results. ${ }^{5,8,21-24}$ This superiority of graft patency rate in this study may be due to fixed management protocol with combined antiplatelet and anticoagulant therapy.

It was observed that, only CABG surgery is not sufficient to provide total revascularization in presence of complex CAD with diffuse lesion, stent restenosis, and LV dysfunction, where need to do concurrent coronary endarterectomy in addition to CABG to achieved good distal run-off and better postoperative outcome. However, surgical skills and 
postoperative anticoagulation therapy remains the key stream in our study and CE was not found to be independently associated with mortality in the analysis for the predictors of mortality.

\section{Conclusion}

Coronary endarterectomy is feasible and a good surgical option for total myocardial revascularization in patients with diffuse coronary artery disease with excellent long-term survival rates and graft patency rates. Furthermore, CE provides optimal myocardial revascularization resulting improvement of postoperative left ventricular function as well as NYHA functional class. However, surgical skill, patient's selection criteria, and postoperative anticoagulation therapy are the key words for better outcome following CE with $\mathrm{CABG}$ surgery. Altogether, endarterectomy should not take the place of CABG procedure, but this technique is an adjunctive to CABG surgery in diffuse calcified coronary artery disease, and CE is not expedient for every IHD patient undergoing coronary artery bypass surgery.

\section{Acknowledgement}

Authors thank all the study participants for their enthusiastic supports to ensure the plenitude, and perfection of the research registry data.

Conflict of Interest: Authors declared no potential conflict of interest in respect to either authorship or research work.

\section{References}

1. Song Y, Xu F, Du J, Zhang J, Feng W. Coronary endarterectomy with coronary artery bypass graft decreases graft patency compared with isolated coronary artery bypass graft: a meta-analysis. Interact CardioVasc Thorac Surg. 2017; 25:30-36. DOI: doi.org/10.1093/icvts/ivx045

2. Bailey CP, May A, Lemmon WM. Survival after coronary endarterectomy in man. J Am Med Assoc. 1957; 164:641-46.

DOI: doi.org/10.1001/jama.1957.02980060017005

3. Ranjan R, Adhikary D, Saha H, Saha SK, Hasan K, Adhikary AB. Coronary atheroma $[14 \mathrm{~cm}]$ extracted from the right coronary artery during off-pump coronary artery bypass grafting. Bangabandhu Sheikh Mujib Med Univ J. 2017; 10:97-100.

DOI: doi.org/10.3329/bsmmuj.v10i2.32706

4. Adhikary AB, Ranjan R, Saha H, Saha SK, Adhikary D, Mandal S. A Systemic Review on Coronary
Endarterectomy in Ischemic Heart Disease. Chest Heart Journal. 2017; 41:66-72.

5. Ranjan R, Adhikary D, Acharya M, Chakravarty S, Saha SK, Adhikary AB. Histopathological analysis of the coronary atheroma extracted during coronary artery bypass graft surgery. Bangabandhu Sheikh Mujib Med Univ J. 2018;11: 226-30. DOI: doi.org/10.3329/bsmmuj.v11i3.37827

6. LaPar DJ, Anvari F, Irvine JN, Kern JA, Swenson BR, Kron IL, et al. The impact of coronary artery endarterectomy on the outcomes during coronary artery bypass grafting. J Card Surg. 2011; 26:247-53. DOI: doi.org/10.1111/j.1540-8191.2011. 01247.x

7. Ranjan R, Adhikary D, Mandal S, Seedher A, Adhikary AB. Outcome of coronary endarterectomy with coronary artery bypass grafting in patients with diffuse coronary artery disease in Bangladesh: A retrospective cohort study. JRSM Cardiovasc Dis. 2017;6:1-7.

DOI: doi.org/10.1177/2048004017732658

8. Mills NE. Coronary endarterectomy: surgical techniques for patients with extensive distal atherosclerotic coronary disease. Adv Cardiac Surg. 1998; 10:197-227.

9. Erdil N, Cetin L, Kucuker S, Demirkilic U, Sener E, Tatar H. Closed endarterectomy for diffuse right coronary artery disease: early results with angiographic controls. J Card Surg 2002;17:261-66. DOI:doi.org/10.1111/j.1540-8191.2001.tb 01137.x

10. Ranjan R, Adhikary D, Mandal S, Adhikary AB. Review on coronary endarterectomy- past, present, and future. Int $\mathrm{J}$ current innovation Res. 2017; 3:719-23.

11. Vafaey HR, Salehi Omran MT, Abbaspour S, Banihashem N, Faghanzadeh Ganji G. Anti-coagulation therapy following coronary endarterectomy in patient with coronary artery bypass graft. Caspian J Intern Med. 2018; 9:27-31.

12. Djalilian AR, Shumway SJ. Adjunctive coronary endarterectomy: improved safety in modern cardiac surgery. Ann Thorac Surg. 1995; 60:1749-54. DOI: doi.org/10.1016/0003-4975(95) 00810-1

13. Jones EL, Craver JM, Guyton RA, Bone DK, Hatcher Jr. CR, Riechwald N. Importance of complete revascularization in performance of the coronary bypass operation. Am J Cardiol. 1983; 51:7-12. DOI: doi.org/10.1016/S0002-9149(83) 80003-4

14. Vohra HA, Kanwar R, Khan T, Dimitri WR. Early and Late Outcome After Off-Pump Coronary Artery Bypass Graft Surgery with Coronary Endarterectomy: A SingleCenter 10-Year Experience. Ann Thorac Surg. 2006; 81:1691-96.

DOI: doi.org/10.1016/j.athoracsur.2005.12.028

15. Eryilmaz S, Inan MB, Eren NT, Yazicioglu L, Corapcioglu T, Akalin H. Coronary endarterectomy with off-pump coronary artery bypass surgery. Ann Thorac Surg. 2003; 75:865-69. DOI: doi.org/10.1016/S0003-4975(02) 04500-9

16. Beretta L, Lemma M, Vanelli P. Coronary 'open' endarterectomy and reconstruction: short-and long- 
term results of the revascularization with saphenous vein versus IMA-graft. Eur J Cardiothorac Surg. 1992; 6:382-87.

DOI: doi.org/10.1016/1010-7940(92) 90177-Y

17. Christakis GT, Rao V, Fremes SE, Chen E, Naylor D, Goldman BS. Does coronary endarterectomy adversely affect the result of bypass surgery? J Card Surg. 1993; 8:72-78.

DOI: doi.org/10.1111/j.1540-8191.1993.tb 00577.x

18. Papakonstantinou NA, Baikoussis NG, Apostolakis E. Coronary endarterectomy: New flavors from old recipes. Journal of Cardiology, 2014;63:397-401. DOI: doi.org/10.1016/j.jjcc.2014.02.005

19. Ranjan R, Adhikary AB. Outcome of coronary endarterectomy with off-pump coronary artery bypass grafting: A retrospective study. Bangabandhu Sheikh Mujib Med Univ J. 2017;10: 189-94. DOI: doi.org/10.3329/bsmmuj.v10i2.32706

20. Careaga RG, Salazar GD, Tellez LS, Arguero SR Coronary endarterectomy and bypass grafting without cardiopulmonary bypass. Rev Esp Cardiol. 2003; 56:515-18.
21. Adhikary D, Ranjan R, Mandal S, Adhikary AB. Postoperative Neurological Complications Following Cardiac Surgery. Int $\mathrm{J}$ Current Innovation Res. 2017,3:724-26

22. Gill IS, Beanlands DS, Boyd WD, Finlay S, Keon WJ. Left anterior descending endarterectomy and internal thoracic artery bypass for diffuse coronary disease. Ann Thorac Surg. 1998; 65:659-62. DOI: doi.org/10.1016/S0003-4975(97) 01301-5

23. Ghatanatti R, Teli A. Coronary Endarterectomy: Recent Trends. J Clin Diagn Res. 2017; 11:1-4. DOI: doi.org/10.7860/JCDR/2017/27036.10339

24. Qiu Z, Chen X, Jiang Y, Wang L, Xu M, Huang F, et al. Comparison of off-pump and on-pump coronary endarterectomy for patients with diffusely diseased coronary arteries: early and midterm outcome. J Cardiothorac Surg. 2014; 9:186-94. DOI: doi.org/10.1186/s13019-014-0186-5

25. Naseri E, Sevinc M, Erk MK. Comparison of offpump and conventional coronary endarterectomy. Heart Surg Forum. 2003; 6:216-19. 